Rev. Bras. Saúde Prod. Anim., Salvador, v.17, n.4, p.617-625 out./dez., 2016 http://www.rbspa.ufba.br ISSN 15199940

\title{
Produção de cana-de-açúcar adubada com cama de frango ${ }^{1}$
}

\author{
Sugarcane production fertilized with poultry litter
}

\author{
GUIMARÃES, Geicimara ${ }^{2 *}$; LANA, Rogério de Paula ${ }^{3}$; REI, Renata de Souza ${ }^{4}$; \\ VELOSO, Cristina Mattos ${ }^{5}$; SOUSA, Maria Regina de Miranda ${ }^{6}$; RODRIGUES, \\ Rosane Cláudia ${ }^{7}$ CAMPOS, Silvane de Almeida ${ }^{8}$
}

\author{
${ }^{1}$ Parte da dissertação de Mestrado em Agroecologia/UFV da primeira autora e parte de projeto \\ financiado pelo CNPq (Processo 306.599/2014-7). \\ ${ }^{2}$ Universidade Federal de Viçosa, Viçosa, Minas Gerais, Brasil. Bolsista CAPES. \\ ${ }^{3}$ Universidade Federal de Viçosa, Departamento de Zootecnia, Viçosa, Minas Gerais, Brasil. Bolsista 1B \\ do CNPq. \\ ${ }^{4}$ Universidade Federal de São João Del Rey, Departamento de Zootecnia, São João Del Rey, Minas \\ Gerais, Brasil. \\ ${ }^{5}$ Universidade Federal de Viçosa, Viçosa, Departamento de Zootecnia, Viçosa, Minas Gerais, Brasil. \\ ${ }^{6}$ Pesquisadora da Empresa de Pesquisa Agropecuária de Minas Gerais - EPAMIG, Viçosa, Minas \\ Gerais, Brasil.. \\ ${ }^{7}$ Universidade Federal do Maranhão, Departamento de Zootecnia, Chapadinha, Maranhão, Brasil. \\ ${ }^{8}$ Universidade Federal de Viçosa, Viçosa, Mestrado em Agroecologia, Viçosa, Minas Gerais, Brasil. \\ *Endereço para correspondência: geicimara.guimaraes@ufv.br
}

\section{RESUMO}

Objetivou-se com este trabalho avaliar o desenvolvimento e a qualidade da cana-deaçúcar variedade RB 867515 e os atributos químicos do solo em resposta à aplicação de níveis variáveis de fertilização. Utilizou-se o delineamento experimental em blocos casualizados, com cinco tratamentos $(0,3,6,9 \mathrm{e}$ $12 \mathrm{t} /$ ha de cama de frango) e quatro repetições. Aos quatro meses pós-plantio não houveram diferenças entre os níveis de cama de frango sobre a altura das plantas, diâmetro do colmo, largura da folha e comprimento da folha, mas o número de plantas/m linear e número de folhas/planta atingiram valores máximos utilizando 8,7 e 5,3 t/ha de cama de frango, respectivamente. Aos 12 meses após o plantio foram observados aumentos de $\mathrm{P}, \mathrm{K}, \mathrm{Ca}$ e $\mathrm{Mg}$ pelo incremento no nível de fertilização com cama de frango e aumento linear na produtividade de massa verde da cana. Portanto, pode-se aplicar até $12 \mathrm{t} / \mathrm{ha}$ de cama de frango para maximizar o desempenho da cultura e melhorar a fertilidade do solo. Além da produtividade alcançada, o acúmulo de açúcar solúvel (média de 20 graus Brix), bem como os teores de matéria seca $(32,9 \%)$ e fibra em detergente neutro $(46,7 \%)$ indicam que a cana variedade RB 867515, de ciclo médio/tardio, já se apresenta apropriada para o primeiro corte para alimentação animal aos 12 meses pósplantio.

Palavras-chave: adubação orgânica, canavial, esterco de aves, resíduo, Saccharum officinarum L.

\section{SUMMARY}

The aim of this work was to evaluate the development and quality of sugarcane variety RB 867515 and chemical attributes of the soil in response to the application of increasing level of fertilization. It was used randomized blocks design, with five treatments $(0,3,6,9$ and 12 $\mathrm{t} /$ ha of poultry litter) and four replications. At four months after planting there were no differences among poultry liter levels on plant height, culm diameter, and leaves width and length, but the number of plants/m linear and number of leaves/plant reached maximum values using 8.7 and $5.3 \mathrm{t} /$ ha of poultry litter, respectively. At 12 months after planting, there 
was increase in $\mathrm{P}, \mathrm{K}, \mathrm{Ca}$ and $\mathrm{Mg}$ by increasing the level of fertilization with poultry litter and linear increase in productivity of sugarcane green mass. Therefore, up to $12 \mathrm{t} /$ ha of poultry litter can be applied to maximize the performance of sugarcane and improve soil fertility. In addition to the reached productivity, the accumulation of soluble sugar (mean 20 degrees Brix), as well as contents of dry matter $(32.9 \%)$ and neutral detergent fiber $(46.7 \%)$ indicates that the sugarcane variety RB 867515 , of mean/late cycle, presents appropriate for the first cut for animal feeding at 12 months after planting.

Keywords: organic fertilization, poultry manure, residue, Saccharum spp., sugarcane

\section{INTRODUÇÃO}

No Brasil, a cana-de-açúcar (Saccharum officinarum L.) é de vital importância no contexto socioeconômico e é a principal matéria-prima para produzir etanol como combustível para motores, além de açúcar e forragem para alimentação animal. Determinadas qualidades atribuídas à cultura da cana, como a facilidade de plantio, o desempenho da colheita, precisamente na época de estiagem, e o bom cultivo alcançado no país tornaram-na uma cultura de ampla importância para os produtores. Atualmente, a cana-de-açúcar vem merecendo a atenção de extensionistas e produtores, por apresentar menor custo de produção em comparação com silagem e feno.

No entanto, a busca por sistemas sustentáveis tem sido uma constante. Nesse sentido, é preciso que os produtores tenham novas alternativas viáveis aos fertilizantes químicos de fontes não renováveis, que têm alta participação nos custos de produção. De acordo com Anjos et al. (2007), a substituição da adubação química pela orgânica (cama de frango ou esterco de curral) na fertilização da cana-de-açúcar é viável, sendo que a disponibilidade de cama aviária nas propriedades permite reduzir ou mesmo eliminar por completo a utilização de fertilizantes químicos.

O uso de compostos orgânicos na agricultura ajusta a melhoria das propriedades físicas, químicas e biológicas do solo (ALMEIDA JÚNIOR et al., 2011). Por ser rico em matéria orgânica e nutrientes para o sistema soloplanta, além da deficiência de microrganismos patogênicos, o composto de cama de frango apresenta os principais nutrientes (nitrogênio, fósforo e potássio) em concentrações adequadas para atender $\mathrm{o}$ desenvolvimento das plantas (ATKINSON et al., 1996; SILVA et al., 2011).

Dessa maneira, os estudos sobre a utilização da cama de frango na produção de cana-de-açúcar e a forma como interfere nos atributos químicos do solo poderá contribuir para um sistema de produção mais sustentável, tanto para o produtor de cana para a indústria quanto para uso na alimentação animal.

Dado o grande volume de cama de frango produzido e os altos custos da adubação mineral, objetivou-se com o presente estudo avaliar o desenvolvimento, a qualidade da canade-açúcar e os atributos químicos do solo em resposta à aplicação de níveis crescentes de cama de frango no momento do plantio.

\section{MATERIAL E MÉTODOS}

O estudo foi conduzido no sítio Boa Vista, distrito de Cachoeirinha, Viçosa, $\mathrm{MG}$, pertencente à Universidade Federal de Viçosa, no período de outubro de 2013 a outubro de 2014. A área experimental tem a topografia de encosta e a fim de evitar influências de resíduos 
de adubações anteriores, procurou-se uma área sem manejo há mais de 10 anos.

Antes da implantação do experimento, foi feita análise química do solo, para fins de caracterização, retirando-se amostras ao acaso em toda a área, para a obtenção de uma amostra composta da camada de 0 a $20 \mathrm{~cm}$. A amostra composta foi colocada em saco plástico identificado e encaminhada ao Laboratório de Análise de Solo Viçosa Ltda, apresentando a seguinte composição química: $\mathrm{pH}$ em água $(1: 2,5)$ $=5,6 ; \mathrm{P}=2,1 \mathrm{mg} / \mathrm{dm}^{3} ; \mathrm{P}-\mathrm{rem}=28,7$ $\mathrm{mg} / \mathrm{L} ; \mathrm{K}=41,0 \mathrm{mg} / \mathrm{dm}^{3} ; \mathrm{Ca}^{+2}=1,60$ $\mathrm{cmol}_{\mathrm{C}} / \mathrm{dm}^{3} ; \mathrm{Mg}^{+2}=0,70 \mathrm{cmol}_{\mathrm{c}} / \mathrm{dm}^{3} ; \mathrm{Al}^{+3}$ $=0,00 \quad \mathrm{cmol}_{\mathcal{L}} / \mathrm{dm}^{3} ; \mathrm{H}+\mathrm{Al}=$ $5,12 \mathrm{cmol}_{\mathcal{C}} / \mathrm{dm}^{3} ; \mathrm{SB}=2,40 \mathrm{cmol}_{\mathcal{C}} / \mathrm{dm}^{3}$; $\mathrm{CTC}_{(\mathrm{t})}=2,40 \mathrm{cmol}_{\mathrm{d}} / \mathrm{dm}^{3} ; \mathrm{CTC}_{(\mathrm{T})}=7,52$ $\mathrm{cmol}_{\mathrm{c}} / \mathrm{dm}^{3} ; \mathrm{V}=32,00 \%$; e $\mathrm{m}=0,00 \%$.

$\mathrm{O}$ calcário foi espalhado e incorporado através da aração em agosto de 2013 (dois meses antes do plantio), com base no método da saturação por bases e recomendação para a cultura, utilizandose o equivalente a 4,0 t/ha de calcário dolomítico $(\mathrm{PN}=70,5 \%$; $\mathrm{RE}=99,1 \%$; PRNT $=69,9 \% ; \mathrm{Ca}^{2+}=21,1 \mathrm{dag} / \mathrm{kg}$; $\mathrm{Mg}^{2+}=4,7 \mathrm{dag} / \mathrm{kg}$ ).

Foi feita a aração a aproximadamente $30 \mathrm{~cm}$ de profundidade e gradagem (destorroamento), garantindo a descompactação do solo, reduzindo a infestação de pragas por área e a eliminação da braquiária. Por ocasião do plantio, em outubro de 2013, a sulcagem foi feita mecanicamente, a aproximadamente $30 \mathrm{~cm}$ de profundidade e espaçamento de $1,0 \mathrm{~m}$, utilizando o arado sulcador, sendo retirados os torrões do sulco.

A cama de frango utilizada no experimento foi oriunda de uma granja produtora de frangos no município de Coimbra, MG, de primeiro lote de frangos e com uso de casca de café, sendo coberto com lona e curtida com mensuração de temperatura e revolvimento frequentes, por período de 75 dias. Segundo Paulus et al. (2000), a cama de frango deve ser utilizada bem curtida para evitar que o excesso de amônia na forma de gás cause toxidez nas plantas, principalmente se as mesmas forem plantadas logo após a distribuição do material no solo.

Cinco subamostras de cama de frango foram coletadas ao acaso para a obtenção de uma amostra composta, com vistas à caracterização química, conforme apresentada a seguir: $3,54 \% \mathrm{~N} ; 1,19 \% \mathrm{P}$; $2,96 \% \mathrm{~K} ; 0,496 \% \mathrm{Na} ; 2,39 \% \mathrm{Ca} ; 0,71 \%$ $\mathrm{Mg} ; 0,86 \% \mathrm{~S} ; 18,56 \% \mathrm{CO} ; 5,24 \mathrm{C} / \mathrm{N}$; $530 \mathrm{mg} / \mathrm{kg} \mathrm{Zn} ; 2134 \mathrm{mg} / \mathrm{kg} \mathrm{Fe} ; 538$ $\mathrm{mg} / \mathrm{kg} \mathrm{Mn} ; 67 \mathrm{mg} / \mathrm{kg} \mathrm{Cu} ; 55,70 \mathrm{mg} / \mathrm{kg}$ $\mathrm{B}$; e $\mathrm{pH}=7,2$ e $23,4 \%$ umidade.

$\mathrm{O}$ delineamento experimental utilizado foi em blocos casualizados, com cinco tratamentos (doses de adubação) e quatro repetições, totalizando 20 parcelas experimentais. Os tratamentos consistiram da aplicação de 0 (controle); 3, 6, 9 e 12t/ha de cama de frango. Cada unidade experimental teve $5 \mathrm{~m}$ de comprimento e $4 \mathrm{~m}$ de largura (quatro linhas de plantas espaçadas de $1 \mathrm{~m}$ ), totalizando uma área de $20 \mathrm{~m}^{2}$. Foram utilizadas as duas linhas centrais, descartando-se $\quad 0,50 \mathrm{~m}$ em cada extremidade, ficando, portanto, a área útil de $8 \mathrm{~m}^{2}$.

A cama de frango foi colocada no fundo do sulco e coberta com um pouco de solo para não entrar em contato com a canade-açúcar. Foi utilizada a variedade de cana já existente no sítio, RB 867515, de ciclo médio/tardio e selecionada por apresentar maior produtividade. $\mathrm{O}$ plantio foi feito manualmente em espaçamento de 1,00 m entre linhas e duas fileiras de cana por sulco, sendo picada em tamanhos de $0,20 \mathrm{~m}$ dentro do sulco. O controle de plantas espontâneas foi por capina manual, com auxílio de enxada. 
Aos quatro e dez meses, foram avaliados números de plantas por metro linear, altura da planta (medição do solo até a lígula das folhas mais altas), diâmetro do colmo $(10 \mathrm{~cm}$ da superfície do solo), número de folhas por planta $\mathrm{e}$ comprimento e largura da maior folha. Aos 12 meses foram obtidos os dados de produtividade ( $\mathrm{t} / \mathrm{ha}$ de massa verde), composição química das plantas, grau Brix e avaliação química do solo após o plantio.

Em outubro de 2014, o corte das plantas foi realizado de forma manual, rente ao solo, e as amostras da planta inteira foram picadas, acondicionadas em sacolas plásticas $(500 \mathrm{~g})$ e congeladas para posteriores análises laboratoriais. Após o descongelamento, as amostras foram acondicionadas em sacolas de papel, devidamente identificadas e levadas para estufa com ventilação forçada de ar à $55^{\circ} \mathrm{C}$, por 72 horas, e pesadas em balança semianalítica para a determinação da matéria seca ao ar. Em seguida, as amostras foram moídas e analisadas quanto ao teor de matéria seca a $105^{\circ} \mathrm{C}$, fibra em detergente neutro corrigida para cinzas e proteína (FDNcp), carboidratos não fibrosos $(\mathrm{CNF})$, proteína bruta $(\mathrm{PB})$, extrato etéreo (EE) e cinzas $(\mathrm{Cz})$, segundo Detmann et al. (2012). O grau Brix foi medido em amostras de caldo de cana, provenientes da moagem da cana em engenho elétrico, utilizando sacarímetro (densímetro).

Para averiguar o resultado das doses de adubação sobre as variáveis analisadas, os dados experimentais foram submetidos à análise de variância e regressão por meio do Minitab (RYAN \& JOINER, 1994), utilizando-se, para comparação entre as médias, teste de Tukey, a 5\% de significância.

\section{RESULTADOS E DISCUSSÃO}

$\mathrm{O} \mathrm{pH}$ e o teor de cálcio se apresentaram baixos e o teor de $\mathrm{H}+\mathrm{Al}$ alto no momento do plantio (Tabela 1), embora tenha sido feita calagem na área. Estes resultados podem ter ocorrido em virtude do processo de aração e gradagem do solo após a aplicação do calcário, que revolveu a camada abaixo de $20 \mathrm{~cm}$ para a superfície, uma vez que a amostragem do solo se deu a $0-20 \mathrm{~cm}$. Segundo Oliveira et al. (2007), a eficiência do calcário na correção da acidez do solo depende, dentre outros fatores, da sua granulometria, da distribuição uniforme no campo e da disponibilidade hídrica do solo. Entretanto, o $\mathrm{pH}$ melhorou posteriormente, como pode ser visto na amostra de solo com 0 t/ha de cama de frango após a colheita da cana-de-açúcar (Tabela 1).

De acordo com Santos et al. (2004), os compostos orgânicos são fontes de $\mathrm{P}, \mathrm{K}$, $\mathrm{Ca}, \mathrm{Mg}, \mathrm{Cu}$ e $\mathrm{Zn}$, podendo ser indicados, principalmente, para solos pobres. Para os parâmetros de fertilidade do solo, os compostos promovem benefícios ao solo, favorecendo a elevação do $\mathrm{pH}$, da soma de bases (SB), da capacidade de troca catiônica $(\mathrm{T})$ e da saturação por bases (V\%), além de diminuição da acidez potencial $(\mathrm{H}+\mathrm{Al})$. No presente trabalho, observou-se aumento de $\mathrm{P}, \mathrm{K}$, $\mathrm{Ca}, \mathrm{Mg}, \mathrm{SB}, \mathrm{CTC}(\mathrm{t})$ e $\mathrm{V}$ com uso de cama de frango (Tabela 1), que pode resultar em maior produção da cana-deaçúcar (BULEGON et al., 2012). Segundo a CFSEMG (1999), a quantidade de adubo orgânico e de adubo químico a ser aplicado no sulco de plantio da cana-de-açúcar baseia-se na quantidade de fósforo $\left(\mathrm{P}_{2} \mathrm{O}_{5}\right)$ presente nos adubos e no solo e na necessidade da cultura, variando de 100 a $140 \mathrm{~kg} / \mathrm{ha}$. No presente estudo, este nível foi obtido com 10t/ha de cama de frango. 
Rev. Bras. Saúde Prod. Anim., Salvador, v.17, n.4, p.617-625 out./dez., 2016 http://www.rbspa.ufba.br ISSN 15199940

A matéria seca da cama de frango varia entre 70 e $80 \%$, dependendo do manejo, da composição da ração e do desperdício dos comedouros e bebedouros. Portanto, o conhecimento do teor de matéria seca é importante no cálculo da reposição de nutrientes, exigida pelas culturas. No presente estudo, o teor de matéria seca foi de $76,6 \%$, estando dentro da faixa apresentada acima.

Tabela 1. Atributos químicos do solo no momento do plantio e após a colheita da canade-açúcar (12 meses), em áreas adubadas com níveis crescentes de cama de frango

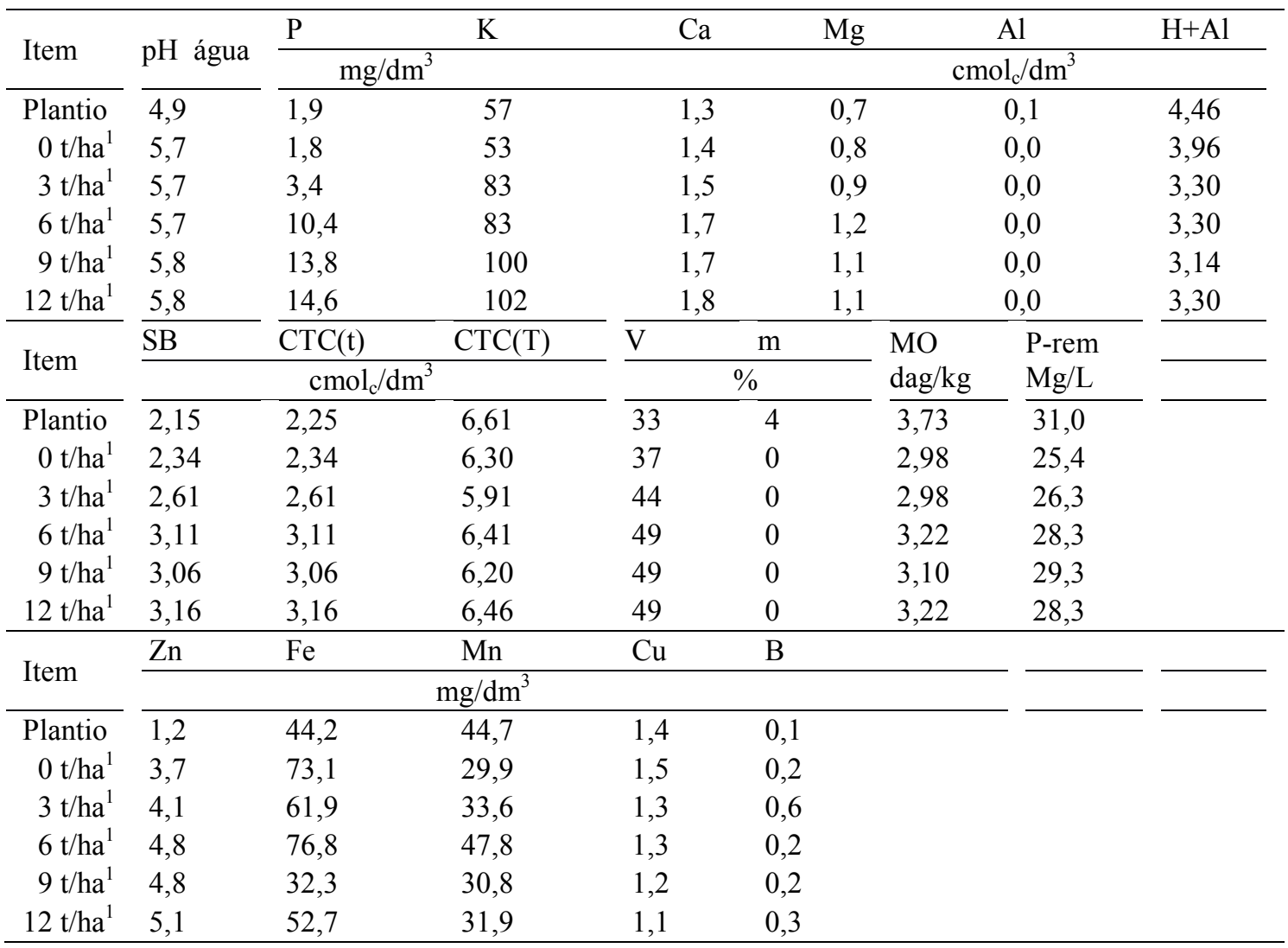

${ }^{1} \mathrm{t} / \mathrm{ha}=$ cama de frango em $\mathrm{t} / \mathrm{ha}$. SB = soma de bases; $\mathrm{CTC}(\mathrm{t})=$ capacidade de troca de cátions efetiva; $\mathrm{CTC}(\mathrm{T})=$ capacidade de troca de cátions a $\mathrm{pH} 7,0 ; \mathrm{V}=$ percentagem de saturação por bases; $\mathrm{m}=$ percentagem de saturação por alumínio; $\mathrm{MO}$ = matéria orgânica; P-rem = fósforo remanescente.

Houve efeito quadrático do nível de cama de frango sobre o número de plantas $/ m$ linear $(P<0,01)$ e sobre $o$ número de folhas/planta $(\mathrm{P}<0,05)$ aos quatro meses após o plantio (Tabela 2), com valor máximo estimado pelos modelos utilizando 8,7 e 5,3t/ha de cama de frango, respectivamente. Por outro lado, não houve efeito $(\mathrm{P}>0,05)$ do nível de cama de frango sobre a altura das plantas, o diâmetro do colmo, a largura e o comprimento da maior folha aos quatro meses (Tabela 2). Esse comportamento se deve ao estádio fenológico da cultura, uma vez que nesse estágio a planta prioriza o perfilhamento, resultando em maior número de plantas $/ \mathrm{m}$ linear com o aumento das doses de cama de frango. Da mesma maneira, ocorreu com o 
Rev. Bras. Saúde Prod. Anim., Salvador, v.17, n.4, p.617-625 out./dez., 2016 http://www.rbspa.ufba.br ISSN 15199940

comprimento da folha, quanto maior a dose de cama de frango maior o comprimento da folha. Já com relação ao número de folhas/planta, verifica-se maiores valores com a aplicação de 3t/ha de cama de frango, decrescendo a partir daí. Em gramíneas, o número de folhas/planta é constante para uma determinada espécie ou cultivar, sendo pouco influenciado pelos fatores do meio, o que explica o comportamento para essa variável (SANTOS et al., 2011).

Tabela 2. Parâmetros de crescimento da cultura de cana-de-açúcar aos quatro meses, em função da adubação orgânica com cama de frango no plantio

\begin{tabular}{|c|c|c|c|c|c|c|c|c|}
\hline \multirow{2}{*}{ Item } & \multicolumn{5}{|c|}{ Cama de Frango (t/ha) } & \multirow{2}{*}{ EP } & \multirow{2}{*}{ Sign. } & \multirow{2}{*}{ ER } \\
\hline & 0 & 3 & 6 & 9 & 12 & & & \\
\hline Plantas/m linear & 8,63 & 9,15 & 12,0 & 9,80 & 10,8 & 0,51 & 0,001 & 1 \\
\hline Altura da planta, $\mathrm{cm}$ & 33,2 & 40,5 & 42,6 & 38,5 & 36,4 & 2,75 & 0,128 & \\
\hline Diâmetro do colmo, mm & 18,8 & 20,7 & 22,0 & 19,4 & 18,3 & 1,37 & 0,173 & \\
\hline Largura da folha, $\mathrm{mm}$ & 31,3 & 33,6 & 35,1 & 34,4 & 33,2 & 1,30 & 0,173 & \\
\hline Comprimento da folha, $\mathrm{cm}$ & 117 & 132 & 133 & 135 & 136 & 4,63 & 0,075 & \\
\hline Número de folhas/planta & 6,06 & 6,63 & 6,31 & 6,38 & 5,94 & 0,14 & 0,035 & 2 \\
\hline
\end{tabular}

Médias seguidas por letras iguais na mesma linha não diferem entre si, pelo teste de Tukey, a $5 \%$ de probabilidade; $\mathrm{EP}=$ erro padrão da média; Sign. = significância pelo teste $\mathrm{F} ; \mathrm{ER}=$ equação de regressão: ${ }^{1} 8,50+0,546 \mathrm{X}-0,0313 \mathrm{X}^{2}, \mathrm{R}^{2}=0,51 ;{ }^{2} 6,13+0,138 \mathrm{X}-0,0129 \mathrm{X}^{2}$, e $\mathrm{R}^{2}=0,73$.

Houve efeito linear decrescente $(\mathrm{P}<0,01)$ do nível de cama de frango sobre o diâmetro do colmo aos dez meses após o plantio (Tabela 3). Não houve efeito $(\mathrm{P}>0,05)$ do nível de cama de frango sobre o número de plantas $/ \mathrm{m}$ linear, a altura das plantas, a largura e o comprimento da maior folha e o número de folhas/planta aos dez meses (Tabela 3). Entretanto, o aumento no número de plantas/m linear na cana-de-açúcar aos quatro meses com o aumento das doses de cama de frango (Tabela 2) acarretou redução no diâmetro do colmo aos 10 meses, devido a maior competição.

Tabela 3 Parâmetros de crescimento da cultura de cana-de-açúcar aos dez meses, e produtividade aos 12 meses, em função da adubação orgânica com cama de frango no plantio

\begin{tabular}{|c|c|c|c|c|c|c|c|c|}
\hline \multirow{2}{*}{ Item } & \multicolumn{5}{|c|}{ Cama de Frango (t/ha) } & \multirow{2}{*}{ EP } & \multirow{2}{*}{ Sign. } & \multirow{2}{*}{ ER } \\
\hline & 0 & 3 & 6 & 9 & 12 & & & \\
\hline Plantas/m linear & 9,20 & 9,23 & 9,30 & 9,53 & 9,60 & 0,57 & 0,500 & \\
\hline Altura da planta, $\mathrm{cm}$ & 132 & 144 & 131 & 136 & 141 & 5,59 & 0,200 & \\
\hline Diâmetro do colmo, $\mathrm{mm}$ & 24,2 & 26,7 & 24,2 & 23,5 & 24,7 & 0,48 & 0,001 & 1 \\
\hline Largura da folha, mm & 50,9 & 53,1 & 55,4 & 53,0 & 51,2 & 2,29 & 0,220 & \\
\hline Comprimento da folha, $\mathrm{cm}$ & 91 & 124 & 124 & 122 & 123 & 21,4 & 0,230 & \\
\hline Número de folhas/planta & 6,31 & 6,44 & 6,25 & 5,94 & 6,19 & 0,14 & 0,210 & \\
\hline Produtividade de $\mathrm{MV}, \mathrm{t} / \mathrm{ha}$ & 57,7 & 81,2 & 71,3 & 72,5 & 97,2 & 7,93 & 0,039 & 2 \\
\hline
\end{tabular}

Médias seguidas por letras iguais na mesma linha não diferem entre si, pelo teste de Tukey, a 5\% de probabilidade; $\mathrm{EP}=$ erro padrão da média; Sign. = significância pelo teste $\mathrm{F}$; ER = equação de regressão: ${ }^{1} 25,1-0,07 \mathrm{X}, \mathrm{r}^{2}=0,08 ;{ }^{2} 61,9+2,34 \mathrm{X}, \mathrm{r}^{2}=0,26$; e MV = massa verde. 
Rev. Bras. Saúde Prod. Anim., Salvador, v.17, n.4, p.617-625 out./dez., 2016 http://www.rbspa.ufba.br ISSN 15199940

Segundo Oliveira et al. (2011), o diâmetro do colmo depende das características genéticas da variedade, do número de perfilhos, do espaçamento utilizado, da área foliar e das condições ambientais.

Houve efeito linear crescente $(\mathrm{P}<0,05)$ do nível de cama de frango sobre a produtividade de massa verde aos 12 meses (Tabela 3 ) sendo que, no presente estudo, a melhor produtividade foi obtida com 12 t/ha de cama de frango. Apesar das doses crescentes promoverem redução no diâmetro do colmo, não houve comprometimento na produção total da cana-de-açúcar. Há poucos trabalhos sobre o uso de cama de frango na fertilização de culturas em anos recentes e sobre a eficiência com que os nutrientes dos mesmos são usados (DELVE et al., 2001; BLAISE et al., 2005; SALAZAR et al., 2005).
Os teores médios de matéria seca e fibra em detergente neutro obtidos no presente estudo aos 365 dias foram de 32,9 e $46,7 \%$, respectivamente, variando pouco em função dos tratamentos (Tabela 4). Azevedo et al. (2003) observaram para cana-de-açúcar desta mesma variedade (RB 867515) aos 426 e 549 dias valores de 27,1 e $30,6 \%$ de MS e 50,1 e $47,8 \%$ de FDN, respectivamente, e Santos et al. (2006) apresentaram para a cana-de-açúcar variedade RB 72-454 valor de FDN de $48,6 \%$. Portanto, os resultados do presente estudo são próximos aos relatados pelos referidos autores, mostrando que a cana variedade RB 867515, mesmo sendo de variedade de ciclo médio/tardio, já apresenta composição apropriada para o primeiro corte aos 12 meses para uso na alimentação animal.

Tabela 4. Composição química da cana-de-açúcar aos 12 meses, em função da adubação orgânica com cama de frango no plantio

\begin{tabular}{cccccccc}
\hline $\begin{array}{l}\text { Cama de frango } \\
\text { (t/ha) }\end{array}$ & $\%$ MS & $\begin{array}{c}\text { \%FDNcp } \\
\text { na MS }\end{array}$ & $\begin{array}{c}\% \text { CNF na } \\
\text { MS }\end{array}$ & $\begin{array}{c}\text { \%PB na } \\
\text { MS }\end{array}$ & $\begin{array}{c}\text { \%EE na } \\
\text { MS }\end{array}$ & $\begin{array}{c}\text { \%Cz na } \\
\text { MS }\end{array}$ & ${ }^{\circ}$ Brix \\
\hline 0,00 & 33,10 & 44,70 & 50,20 & 2,25 & 0,79 & 2,12 & 21,50 \\
3,00 & 34,20 & 51,00 & 44,00 & 1,91 & 0,95 & 2,17 & 21,50 \\
6,00 & 33,00 & 45,00 & 49,40 & 2,27 & 0,90 & 2,34 & 17,50 \\
9,00 & 31,80 & 47,90 & 46,40 & 2,17 & 1,00 & 2,57 & 21,00 \\
12,00 & 32,30 & 45,10 & 49,60 & 2,25 & 0,64 & 2,42 & 18,00 \\
Média & 32,90 & 46,70 & 47,90 & 2,17 & 0,86 & 2,33 & 19,90 \\
DP & 0,90 & 2,70 & 2,60 & 0,15 & 0,14 & 0,18 & 1,70 \\
CV & 2,80 & 5,80 & 5,50 & 7,00 & 16,90 & 8,00 & 8,60 \\
\hline
\end{tabular}

$\mathrm{MS}=$ matéria seca; FDNcp $=$ fibra em detergente neutro corrigido para cinzas e proteína; $\mathrm{CNF}=$ carboidratos não fibrosos; $\mathrm{PB}=$ proteína bruta; $\mathrm{EE}=$ extrato etéreo; $\mathrm{Cz}=$ cinzas; $\mathrm{DP}=$ desvio padrão; e $\mathrm{CV}=$ coeficiente de variação $(\%)$.

Os valores de grau Brix obtidos no presente estudo foi igual ou superior a 18 , exceto para $6 \mathrm{t} / \mathrm{ha}$ de cama de frango, que apresentou valor de 17,5 (Tabela 4). Rodrigues et al. (1997) obtiveram grau Brix de 17,8 para a variedade RB 72-454, com 450 dias, e Muraro et al. (2009) obtiveram grau
Brix de 17,4 para a mesma variedade, com 420 dias, adubada com $500 \mathrm{~kg} / \mathrm{ha}$ de N, P, K, na proporção de 02-20-18.

Com base no exposto conclui-se que a adubação com cama de frango melhora as características químicas do solo, aumenta a produção da cana-de-açúcar e exerce pouca influência na sua 
Rev. Bras. Saúde Prod. Anim., Salvador, v.17, n.4, p.617-625 out./dez., 2016 http://www.rbspa.ufba.br ISSN 15199940

composição química aos 12 meses após o plantio, sendo que 12t/ha (maior nível utilizado) permite maximizar o desempenho da cultura. Além da produtividade alcançada, o acúmulo de açúcar solúvel (média de 20 graus Brix), bem como os teores de matéria seca $(32,9 \%)$ e fibra em detergente neutro $(46,7 \%)$ indicam que a cana variedade RB 867515, de ciclo médio/tardio, já se apresenta apropriada para o primeiro corte para alimentação animal aos 12 meses pós-plantio.

\section{REFERÊNCIAS}

ALMEIDA JÚNIOR, A.B.; NASCIMENTO, C.W.A.; SOBRAL, M.F.; SILVA, F.B.V.; GOMES, W.A. Fertilidade do solo e absorção de nutrientes em cana-de-açúcar fertilizada com torta de filtro. Revista Brasileira de Engenharia Agrícola e Ambiental, v.15, n.10, 2011.

ANJOS, I.A.; ANDRADE, L.A.B.; GARCIA, J.C.; FIGUEIREDO, P.A.M.; CARVALHO, G.J. Efeito da adubação orgânica e da época de colheita na qualidade da matéria prima e nos rendimentos agrícola e de açúcar mascavo artesanal de duas cultivares de cana de açúcar (cana-planta). Ciência e Agrotecnologia, v.31, n.1, p.59-63, 2007.

ATKINSON, C. F.; JONES, D.D.; GAUTHIER, J. Biodegradability and microbial activities during composting of poultry litter. Poultry Science, v.75, n.5, p.608-617, 1996.

AZEVEDO, J.A.G.; PEREIRA, J.C.; QUEIROZ, A.C.; CARNEIRO, P.C.S.; LANA, R.P.; BARBOSA, M.H.P.; FERNANDES, A.M.; RENNÓ, F.P. Composição químico bromatológico, fracionamento de carboidratos e degradação in vitro da fibra de três variedades de cana-de-açúcar (Saccharum ssp.). Revista Brasileira de Zootecnia, v.32, n.6, p.1443-1453, 2003.

BLAISE, D.; SINGH, J.V.; BONDE, A.N.; TEKALE, K.U.; MAYEE, C.D. Effects of farmyard manure and fertilizers on yield, fibre quality and nutrient balance of rainfed cotton (Gossipium hirsutum). Bioresource Technology, v.96, p.345-349, 2005.

BULEGON, L.G.; CASTAGNARA, D.D.; ZOZ, T.; OLIVEIRA, P.S.R.; SOUZA, F.H. Análise econômica na cultura do milho utilizando adubação orgânica em substituição à mineral.

Ensaios e Ciência: Ciências

Biológicas, Agrárias e da Saúde, v.16, n.2, p.81-91, 2012.

COMISSÃO DE FERTILIDADE DO

SOLO DO ESTADO DE MINAS GERAIS - CFSEMG. Recomendações para uso de corretivos e fertilizantes em Minas Gerais: 5ed. Viçosa, MG, 1999. 360p.

DELVE, R.J.; CADISCH, G.; TANNER, J.C.; THORPE, W.; THORNE, P.J.; GILLER, K.E. Implications of livestock feeding management on soil fertility in the smallholder farming systems of subSaharan Africa. Agriculture, Ecosystems \& Environment, v.84, p.227-243, 2001.

DETMANN, E.; SOUZA, M.A.; VALADARES FILHO, S.C.; QUEIROZ, A.C.; BERCHIELLI, T.T.; SALIBA, E.O.S.; CABRAL, L.S.; PINA, D.S.; LADEIRA, M.M.; AZEVEDO, J.A.G. Métodos para análise de alimentos. Visconde do Rio Branco, MG: UFV, 2012. 214p. 
Rev. Bras. Saúde Prod. Anim., Salvador, v.17, n.4, p.617-625 out./dez., 2016 http://www.rbspa.ufba.br ISSN 15199940

MURARO, G.B.; JÚNIOR, P.R.; OLIVEIRA, V.C.; GRANZOTTO, P.M.C.; SCHOGOR, A.L.B. Efeito da idade de corte sobre a composição bromatológica e as características da silagem de cana-de-açúcar plantada em dois espaçamentos e três idades de corte. Revista Brasileira de Zootecnia, v.38, n.8, p.1525-1531, 2009.

NAKAMAE, I.J. (Ed.). Anualpec: anuário da pecuária brasileira. São Paulo: FNP, 2004. p.191-232.

OLIVEIRA, F.M.; ASPIAZÚ, I.; KONDO, M.K.; BORGES, I.D.; PEGORARO, R.F.; VIANNA, E.J. Crescimento e produção de variedades de cana-de-açúcar influenciadas por diferentes adubações e estresse hídrico.

Revista Trópica - Ciências Agrárias e Biológicas, v.5, n.1, p.56, 2011.

OLIVEIRA, M.W.; FREIRE, F.M.; MACÊDO, G.A.R.; FERREIRA, J.J. Nutrição mineral e adubação da canade-açúcar. Informe Agropecuário, v.28, n.239, p.30-43, 2007.

PAULUS, G.; MULLER, A.M.; BARCELLOS, L.A.R. Agroecologia aplicada: práticas e métodos para uma agricultura de base ecológica. Porto Alegre: EMATER-RS, 2000. 86p.

RODRIGUES, A.A.; PRIMAVESI, O.; ESTEVES, S.N. Efeito da qualidade de variedades de cana-de-açúcar sobre seu valor como alimento para bovinos.

Pesquisa Agropecuária Brasileira, v.32, n.12, p.1333-1338, 1997.

RYAN, B.F.; JOINER, B.L. Minitab handbook. 3.ed. Belmont: Duxbury Press, 1994. 448p.
SALAZAR, F.J.; CHADWICK, D.; PAIN, B.F.; HATCH, D.; OWEN, E. Nitrogen budgets for three cropping systems fertilized with cattle manure. Bioresource Technology, v.96, p.235245, 2005.

SANTOS, C.C.; BELLINGIERI, P.A.; FREITAS, J.C. Efeito da aplicação de compostos orgânicos de cama de frango nas propriedades químicas de um Latossolo Vermelho Escuro cultivado com sogro granífero [Sorghum bicolor (L.) Moench]. Científica, v.32, n.2, p.134-140, 2004.

SANTOS, R.V.; EVANGELISTA, A.R.; PINTO, J.C.; COUTO FILHO, C.C.C.; SOUZA, R.M. Composição química da cana-de-açúcar e das silagens com diferentes aditivos em duas idades de corte. Ciência e Agrotecnologia, v.30, n.6, p.11841189, 2006.

SANTOS, M.E.R.; FONSECA, D.M.; BRAZ, T.G.S.; SILVA, S.P.; GOMES, V.M.; SILVA, G.P. Características morfogênicas e estruturais de perfilhos de capim-braquiária em locais do pasto com alturas variáveis. Revista

Brasileira de Zootecnia, v.40, n.3, p.535-542, 2011.

SILVA, T.R.; MENEZES, J.S.F.; SIMON, G.A.; ASSIS, R.L.; SANTOS, C.J.L.; GOMES, G.V. Cultivo do milho e disponibilidade de $\mathrm{P}$ sob adubação com cama-de-frango. Revista Brasileira de Engenharia Agrícola e Ambiental, v.15, n.9, 2011.

Data de recebimento: $23 / 11 / 2015$

Data de aprovação: 31/08/2016 